\title{
NO RASTRO DA COBRA-CANOA: RELIGIÃO, CULTURA E EDUCACÃO NO ALTO RIO NEGRO - AM
}

\author{
In the trail of the Cobra-Canoa: religion, culture and educacion in Upper Rio \\ Negro-AM
}

\author{
Roberta Enir Faria Neves de Lima \\ Mestre em Sociedade e Cultura na Amazônia pela \\ UFAM. Atualmente é docente do IFAM - Campus \\ SGC onde presidiu a Comissão de Estruturação do \\ Núcleo Gestor de Estudos Linguísticos e \\ Antropológicos do IFAM. \\ Orcid: http://orcid.org/0000-0001-6311-6308 \\ E-mail: enir@ifam.edu.br
}

Renilda Aparecida Costa Doutorado em Ciências Sociais pela Universidade do Vale do Rio dos Sinos/Unisinos( 2011). Atualmente é professora adjunta da Universidade Federal do Amazonas atuando no Instituto de Natureza e Cultura Benjamin Constant na área da Sociologia da Educação e no Programa de Pós-graduação Sociedade e Cultura na Amazônia. É coordenadora do Núcleo de Estudos Afro Indígena - NEAINC. E-mail: renildaaparecidacosta@gmail.com

Informações do artigo Recebido em: 10/02/2017 Aceito em: 04/05/2017

\begin{abstract}
Resumo
As reflexões são fruto da observação de atividades de pesquisa realizadas pelo Núcleo Gestor de Estudos Linguísticos e Antropológicos, NUGLAN, do Instituto Federal de Educação, Ciências e Tecnologia do Amazonas - Campus São Gabriel da Cachoeira, IFAM CGSC, entre os anos de 2011 e 2013. Através dos relatos obtidos durante a experiência em campo procuramos compreender a concepção de educação oferecida pelos padres Salesianos no Alto Rio Negro às inúmeras etnias da região e assinalar, além do o impacto sofrido por elas com a chegada de missionários da igreja pentecostal na vida das comunidades por conta da demonização de suas tradições. Necessitamos perceber as implicações da educação oferecida pelos padres da ordem e o efeito da presença evangélica nas comunidades indígenas. Palavras chave: Religião. Cultura e educação no Alto Rio Negro.
\end{abstract}

\section{Educação e identidade nacional: a Língua Portuguesa entre os povos Indígenas}

Considerando-se que o foco principal da Ordem Salesiana no Alto Rio Negro é a educação, cabem, aqui, algumas reflexões: Educação Liberta? Qualquer tipo de educação pode libertar? Quem tem acesso a essa educação que proporciona condições de sermos seres reflexivos capazes de decidir por nós mesmos nossos destinos? Fomos "treinados" a acreditar que a resposta à primeira pergunta seria um sonoro sim. Sim a educação liberta, entretanto a segunda pergunta nos traz à mente imagens de modelos de educação que foram adotados no passado e que certamente não contribuíam para o crescimento do indivíduo como membro consciente da sociedade.

Nem todos os membros que fazem parte da sociedade envolvente ou colonizadora têm acesso a uma educação libertadora e isso se dá por fatores históricos e culturais que procuram justificar a ausência desses indivíduos no processo educacional. Nas palavras de 
Darcy Ribeiro (2010): "[...] surgimos da confluência, do entrechoque e do caldeamento do invasor português com índios silvícolas e campineiros e com negros africanos, uns e outros aliciados como escravos..." (RIBEIRO, 2010)

A grande massa resultante dessa confluência durante muito tempo ficou marcada como a causa do nosso atraso e a "distância evolutiva" existente entre nós e os europeus. Os primeiros teóricos estudiosos da formação da sociedade brasileira como Oliveira Vianna e Nina Rodrigues defendiam que a mestiçagem causou nosso atraso e que o branqueamento da sociedade brasileira seria a solução para nossa chegada ao patamar de civilizados. Uma onda migratória de europeus foi estimulada pelos governos do início da República. Alemães, Poloneses, Italianos chegam ao Brasil a fim de trazer o progresso tão esperado que os mulatos não foram capazes de tornar viável.

Nesse cenário, Gilberto Freyre influenciado por sua experiência nos Estados Unidos com o antropólogo Franz Boas, inova a teoria de formação do povo brasileiro afirmando que exatamente aquilo que os teóricos que o antecederam pregavam como ponto fraco em nossa formação, nossa mestiçagem, seria na verdade o que nos torna tão singulares. Sua obra mais editada foi Casa Grande \& Senzala sendo criticada por muitos e igualmente admirada por outros tantos. Segundo COSTA (2011)

A identidade nacional brasileira, também foi influenciada pelo conceito de democracia racial, difundida no cenário mundial a partir da obra Casa Grande e Senzala, de Gilberto Freyre (1933), cujo tema girava em torno da vida social no Brasil, em meados do século XIX. Seu livro pregava a ideologia da harmonia nas relações entre brancos, negros e índios.

Em todo território brasileiro os efeitos dessa visão de patriotismo e nacionalismo pregada pelo governo teve seus efeitos. A tão esperada imigração europeia que, teoricamente, impulsionaria nosso crescimento torna-se um inconveniente e um possível perigo a nossa soberania.

Na Amazônia o indivíduo a ser abrasileirado era o indígena, pois mesmo sendo natural dessa terra não era visto como brasileiro em virtude da grande diversidade étnica e linguística existente entre eles. Fomos educados para acreditar que a Amazônia possui um grande vazio demográfico com áreas imensas desabitadas. Contudo, através de uma visão mais reflexiva é possível observarmos que, na verdade o que ocorria era que as autoridades ao dizerem que havia um vazio demográfico a ser preenchido com colonos de outras regiões (brancos) sinalizavam que para elas os índios que ali residiam há gerações não contabilizavam como 
gente e sim como seres incapazes de zelar por nossas fronteiras e nossas riquezas. Em outras palavras: não havia gente morando lá, havia índios. No Norte do país o Estado Brasileiro não se fazia presente e através das ações da Ordem Salesiana foi possível levar o conceito de brasilidade, cidadania, e assegurar, dessa forma, nossas fronteiras territoriais. Ao se tornar bom cristão e bom cidadão, o indígena garantia ao Estado a soberania sobre o território.

Parte integrante da identidade de um povo, a língua é um marcador importante que auxilia na delimitação das fronteiras étnicas, como afirma Weber no livro Economia $e$ Sociedade, no capítulo intitulado As relações comunitárias étnicas, pois essas pessoas guardam lembranças ancestrais que articulam o passado com o presente a fim de manter a unicidade do grupo. Manter essa conexão não foi fácil para os estrangeiros que imigraram para o Brasil a partir da década de 30, contudo, para os indígenas que em virtude da visão colonial sofreram com discriminação e abusos, a mão do Estado Colonial e depois do Estado Brasileiro apertou mais e mais forte suas gargantas tentando descaracterizá-los e torná-los apenas brasileiros. Os povos indígenas, não obstante as formulações arqueológicas sobre a ocupação do território, podem ser considerados autóctones.

A imposição de um Português padrão idealizado por uma elite branca que padronizou a variante falada por ela como sendo a certa, tornando marginal um sem número de indivíduos que não dominam o idioma, independentemente de serem germânicos, índios e negros ou apenas pessoas pobres da periferia das grandes cidades. Se você não domina a forma escrita ou falada do chamado Português padrão.Todos esses agentes sofriam e ainda sofrem devido ao o que Marcos Bagno chama de preconceito linguístico. O preconceito linguístico a que se refere o autor é alimentado por mitos acerca da língua portuguesa que perenizam o mesmo (BAGNO, 2007). Nas palavras de Marcus Maia esse preconceito é responsável pelo desprestígio dessas línguas e por seu desaparecimento.

O preconceito de que os indígenas brasileiros são alvos por parte de muitos brasileiros não indígenas é, sem dúvida, um dos fatores responsáveis pelo desprestígio, enfraquecimento e desaparecimento de muitas línguas indígenas no Brasil. (MAIA, 2008)

Guiados pela ideia da superioridade linguística da língua portuguesa e com o objetivo de civilizar os índios, os salesianos procuraram trazer os povos do Alto Rio Negro para junto da sociedade nacional através de uma educação cristã que renegou os valores tradicionais e procurou formar profissionalmente esses jovens como carpinteiros, pedreiros, pintores, com 
relação as jovens eram ensinadas a cozinhar e a costurar. Não era previsto o surgimento de um sujeito agente, capaz de determinar seu próprio destino. Essa empreitada de civilizar o índio que na região do Alto Rio Negro teve início nos idos de 1914 e dura até hoje, provocou mudanças profundas nas estruturas sociais, políticas e étnicas da Região do Alto Rio Negro.

\section{Alto Rio Negro: Região descoberta e redescoberta}

Considerada a região mais indígena do Brasil, o Alto Rio Negro compreende Terras Indígenas Demarcadas de forma contínua que somam 11 milhões de hectares, quase 90\% da área do município de São Gabriel. Fronteira com a Colômbia e Venezuela, possui 23 povos indígenas, que somam mais de $76 \%$ dos habitantes da região do alto Rio Negro (IBGE 2010) distribuídos entre a sede e 732 comunidades que estão à beira dos rios que formam a maior bacia de águas pretas do mundo.

\section{Famílias Linguísticas Do Alto Rio Negro}

Família Linguística Tukano Oriental

Os grupos étnico-linguísticos da Família linguística Tukano Oriental ocupam o rio Uaupés, Tiquié, Papuri, Querari, curso alto do Rio Negro (principalmente entre Santa Isabel e a foz do rio Uaupés, inclusive na cidade de São Gabriel da Cachoeira). Curicuriari, Apapóris (e seu afluente Traíra) e Departamentos do Valpés e Guaviari, estas últimas na Colômbia. São as seguintes etnias: Tukano, Desana, Kubeo, Wanana, Tuyuka, Pira-tapuya, Miriti-tapuia, Arapaso, Karapanã, Bará, Siriano, Makuna, Tatuyo, Yurutí, Barasana, Taiwano. (mapa-livro, 1988, p. 31).

Família Linguística Aruak

Os grupos étnico-linguísticos da Família linguística Aruak ocupam o rio Içana, Ayari, Cuyari, Xié, curso alto do rio Negro (a montante da cidade de Santa Isabel, sobretudo acima da foz do Uaupés), médio e alto curso do rio Uaupés (entre Ipanoré e Periquito), departamento de Guainia (Colômbia) e no Estado Amazonas (Venezuela) São as etnias seguintes: Baré, Baniwa, Werekena, Tariano, Kuripaco (mapa-livro, 1988, p. 31). 
Família Linguística Maku (Nadahup)

Os grupos étnico-linguístico da Família Maku (Nadahup) ocupam a região entre Tiquié, Uaupés e Papuri, afluentes da margem direita do rio Tiquié (principalmente os grandes igarapés Castanha, Cunuri e Ira), Apapóris e Traíra, nas proximidades da cidade de São Gabriel da Cahoeira (do outro lado do rio) até a foz do rio Curicuriari e Marié, Uneiuxi e no Paraná Boá-Boá (médio Japurá), Teá e Departamento do Valpés e Guaviari sendo parte formadas pelas etnias dâw, hupda, yhupdeh, nadöb, kakwa, nukak(Colômbia) (mapa-livro, 1988, p. 31).

Família Linguística Yanomami

Os falantes da família Yanomami ocupam a região das bacias dos rios Padauiri, Marauiá, Inambu e Cauaburi. O grupo yanomami assim se divide: Yanomami, Yanam, Yanomam, Sanuma (MAPA-LIVRO, 1988, p. 31.).

\section{Mitologia e Religião no Alto Rio Negro}

Assim contavam os ancestrais, em torno do fogo, a história de como se deu a criação do homem.

Antigamente não existiam os seres humanos, nem a terra, mas já existia um ser que os indígenas consideravam como um Ser Supremo. O nome dele era $\forall m \forall k o h o ́ ~ Y e ̂ h k \forall$. Ele foi o responsável pela criação da Ye'pá Mahsõ, que, por sua vez, tem a missão de criar o mundo e os seres humanos. Entretanto, ela criou apenas o mundo. Quando criou a Terra, ele viu que seria bom criar alguém que a habitasse; sendo assim, criou dois seres que auxiliariam na criação da humanidade, i.e., são eles Umukohó Mash (ancestral dos Desana) e Ye'pa Mahs (ancestral dos Tukano). Eles auxiliaram na criação dos demais seres e da terra. Para isso tiveram a ajuda de Pa'mఈri-Y甘hk甘s $\forall$ (Canoa da transformação), que na verdade era uma cobra grande. Após criados, os homens ficaram em um lugar místico. O nome desses humanos recém criados é Pa'muri-mahsã, que quer dizer "gente da transformação".

Após todos os humanos terem embarcado, a viagem começou. A embarcação seguiu do Leste para o Oeste. No caminho iam descendo seres encantados que executavam tarefas e iam ficavam pelo caminho. Quem conduziu a viagem foi Um $\forall$ kohó Mash $\forall$ e Ye'pa Mahs $\forall$ Todas as tarefas executadas por eles foram muito importantes, pois ajudaram no desenvolvimento físico e espiritual do homem que estava por nascer. Os homens ainda não tinham nascido fisicamente, pois estavam dentro da Cobra-Canoa esperando o momento de saírem. 
Depois de muito tempo de viagem eles chegam até um lugar chamado Pamuri pe'e, no rio Uaupés, onde os humanos tiveram sua transformação final, tornando-se humanos de fato, como os conhecemos hoje. A partir daí os humanos passaram a desembarcar em um único lugar: esses eram os ancestrais das tribos. Cada ancestral recebeu um lugar onde poderia aperfeiçoar tudo o que aprenderam durante a viagem e assim deixar uma herança para as gerações que viriam. A viagem continua pelos afluentes do Uaupés e rio Tiquié, cruzando todo o continente sul americano e entregando todos os povos indígenas da região nas suas moradas tradicionais. Chega ao fim a viagem do Barco da transformação e dos Pa'miri-mahsã, gente da transformação. Após cumprida a missão, os seres sagrados e a Canoa da Transformação sobem para o céu.

(Prof. Joscival Vasconcelos Reis - Etnia Tukano - autodenominada Ye'pamahsã) ${ }^{1}$ (Yanomami Peripö Yei - "Os Yanomami são filhos do sangue da lua")

No começo Periporiwë era o criador de tudo. Mas ele sofre transformação e vira um monstro. O povo que vivia com Periporiwë começa a ser assassinado e ninguém sabe quem é o assassino. Um menino é morto e quando seu pai o encontra sem vida, o crema. O povo, triste, deixa o lugar. Suhirina quer descobrir quem é o assassino e se esconde para surpreendê-lo e descobrir quem está matando o povo. Com o nascer do dia aparece Periporiwë no lugar onde o menino foi cremado. Periporiwë assume que está matando seu próprio povo.

Suhirina ouve e admirado com aquilo vai chamar o povo para matar Periporiwë. O povo de tristeza não quis voltar. Uhutimãrĩwë foi o único a responder ao chamado de Suhirina para caçar Periporiwë. Uhutimãrĩwë não teve coragem de enfrentar Periporiwë. Suhirina ordena que Uhutimãrĩwë ataque, mas esse falha (Panema). Periporiwë estava fugindo devagar para sua casa no céu. Suhirina (Marupiara) com uma única flecha atinge o coração do monstro. Periporiwë grita: PERIPORI! Quando ele grita seu sangue cai no chão e dele surgem pessoas que gritavam e lutavam. Nessa confusão, Suhirina e Uhutimãrĩwë morrem. Do sangue derramado nasce o povo Yanomami. O Povo Yanomami é filho do sangue de Periporiwë (a Lua).

(Sarney Barbosa Góes - Estudante da Licenciatura Intercultural em Física da etnia Yanomami; Etnia Yanonami clã Kapuriweteri) ${ }^{2}$

A literatura ocidental tem suas origens nos mitos gregos de llíada e Odisseia, entretanto, esses mitos refletem um paradigma ocidental, um paradigma eurocêntrico ${ }^{1}$ e são vistos pela ciência de forma diferente dos mitos criacionais indígenas. O debate a respeito das questões étnicas obrigatoriamente passa pela observância das particularidades culturais

\footnotetext{
${ }^{1}$ Docente de língua Portuguesa do IFAM - Campus São Gabriel da Cachoeira. Membro do Núcleo Gestor de Estudos Linguísticos e Antropológicos IFAM/CSGC. Indígena da etnia Tukano.

2 Acadêmico do Curso de Licenciatura Intercultural em Física - IFAM/CSGC. Membro da etnia Yanomami.
} 
das etnias abordadas. Para tanto iniciamos com as observações e leituras realizadas sobre o passado histórico da Amazônia para podermos compreender quem são os povos dos quais estamos falando.

Os arqueólogos quando retomam as hipóteses que analisam a origem do homem americano, dão prioridades àquela de que o ameríndio, não sendo autóctone, teria vindo para a América, através do estreito de Behring, migração essa feita por grupos asiáticos, a partir da Sibéria, quando o nível do mar baixou e criou uma ponte terrestre. O resultado de tais migrações deu origem a uma enorme diversidade de culturas e diferentes formas de organização, desde as mais complexas, como as civilizações dos Maias, Incas e Astecas [...] até aquelas culturas sem Estado organizado, como as que habitavam o território brasileiro. (FREIRE et al., 2008, p. p. 13).

Com o início do processo colonizador na região Amazônica o contato entre o colono europeu e o nativo fez com que as instituições milenares existentes nas sociedades tribais locais ruíssem. Introduziram-se longas jornadas de trabalho e diferentes papéis na sociedade que antes não existiam. Servos e senhores; donos de terra e desterrados; empregados explorados. Há também aqueles que abraçaram a fé cristã tornando-se membros ativos da igreja, animadores de atividades, catequistas, padres e freiras. Subverteram-se e demonizaram-se crenças locais, rotas de comércio foram extintas e as relações étnicas existentes foram redefinidas. Economicamente, povos que eram tradicionalmente agricultores passaram a ser coletores. (FREIRE et al, 2008)

Do ponto de vista do colonizador houve o povoamento da região, para as populações nativas, entretanto, o ocorrido foi um verdadeiro desastre. Segundo FREIRE et al (2008), o cônego Manoel Teixeira, vigário de Belém, no leito de morte, deixou uma declaração a esse respeito, datada e juramentada de 5 de janeiro de 1654 e com o seguinte teor:

No espaço de 32 annos que á, que se começou conquistar este Estado (do Maranhão e Grão-Pará) são extintos a trabalho e a ferro, secundo a conta dos que o ouvirão, mais de 2.000 .000 (dous milhões) de índios de mais de quatrocentas aldeãs, ou para melhor dizer, cidades muito populosas. (Cônego Manoel 5 de janeiro de 1654. In: FREIRE et al, 2008, p. 20).

Nas palavras de Joseph Campbel "o material do mito é o material da nossa vida, do nosso corpo, do nosso ambiente[...]" (CAMPBEL, 2015, p.7), sendo assim parte integrante da existência humana e das sociedades que dela se valem. Por vários séculos os indígenas da 
Região o Alto Rio Negro criaram e mantiveram seus mitos nas vivencias cotidianas. Isso tudo muda com a chegada de novos atores, sejam eles os conquistadores ou ordens religiosas que impuseram seus costumes, língua e religião.

\section{Os Salesianos: quem são e de onde vieram?}

Nós, salesianos, cumprindo a ordem do santo fundador, S. João Bosco, procuramos atrair a nós a juventude, colocando-a nos internatos, com escolas, oficinas e trabalhos agrícolas. Verificamos, pela experiência, que esse é, ainda, o melhor sistema para conduzir também os adultos à civilização e à luz do evangelho. (GIACONNE, 1949, p. 3 apud CAMARGO; ALBUQUERQUE, 2002)

No início do século $X X$ homens e mulheres impregnados de fervor religiosos e intencionando fazer a obra de Deus, se dirigiram ao Alto Rio Negro a fim de levar o Evangelho, a "civilização" e tornar os índios da região bons cidadãos e bons cristãos. Nosso artigo procura refletir sobre os efeitos que a presença salesiana teve na população da região bem como sobre o impacto posterior gerado pela presença de nova leva missionária na região, advinda da vertente evangélica pentecostal dentro do sistema educacional formal e da educação tradicional indígena.

Fundada por D. João Bosco no ano de 1869 em Turim na Itália, a Pia Sociedade de São Francisco de Sales ou Congregação Salesiana teve o objetivo original de resgatar das ruas os jovens e crianças que vieram do interior do país com suas famílias por força do êxodo rural e foram compelidos a passar fome. Vítimas da industrialização e do capitalismo no final do século XIX esses jovens encontram, entre os salesianos, a oportunidade de abrigo, educação e formação profissional, sendo dessa forma integrados à sociedade. O foco principal da Ordem era a educação (SMILJANIC, 2002).

No Brasil, a ação salesiana junto às etnias indígenas tem início no final do século XIX, no Mato Grosso, onde a ordem funda uma missão para se instalar junto aos Bororo. Em 1915 D. Balzola, que dirigia a missão, é mandado para São Gabriel da Cachoeira - AM a fim de estabelecer as primeiras missões na região do Alto Rio Negro. O intercâmbio missionário era intenso e uma vasta literatura foi produzida por eles (SMILJANIC, 2002).

A vila de Mariuá, hoje Barcelos, foi a capital da província do Rio Negro e sediou um posto de triagem onde o Padre Jesuíta Avogardi "inventariava" os indígenas e os encaminhava para seus destinos (WRIGHT, 2008). 
Em busca de escravos para a exploração de drogas do sertão, colonizadores intensificaram suas incursões pelo Médio Rio Negro no século XVII, quando, então, as populações do Alto Rio Negro começaram a conhecer objetos da cultura européia (facas, machados, etc.), principalmente por meio de comércio interétnico. Após a dizimação de etnias do Médio Rio Negro e, posteriormente, com a derrota da resistência dos índios Manáo nessa região, as agências de contato chegam ao Alto Rio Negro conduzindo processos de escravatura, violentas incursões militares e catequese realizada por distintas congregações católicas. Registra-se um hiato da presença missionária na região entre 1887 e 1914, quando chegaram os missionários salesianos que permanecem até a atualidade. Especificamente em lauaretê, estes se instalaram no ano de 1929 (RAMIREZ, 1997 apud TOLEDO; GIATTI; PELICIONI, 2008).

A presença religiosa foi uma constante na região a partir do século $X X$, quando chegam os primeiros salesianos. Após a sua vinda muito mudou na vida e na rotina das pessoas da região. Suas línguas e identidades étnicas que já nos tempos dos colonizadores portugueses eram vistas como coisas bárbaras e inferiores, nesse momento sofrem um processo de demonização. Lideranças tradicionais, como os pajés, bayá, perdem seu prestígio e o respeito das aldeias que são chamadas, agora, de comunidades. Há o recrutamento dos jovens indiozinhos para serem educados pelos padres dentro da missão. Essa educação era vista pelos pais como a chance de seus filhos tornarem-se "iguais aos salesianos". Os resultados dessa educação são sentidos até os dias de hoje.

A Amazônia por ocasião da chegada dos salesianos é um quadro caótico de decadência econômica. O ciclo da borracha perdia seu brilho. Nos rios, regatões exploravam as populações indígenas com preços absurdos e forçando os homens a irem trabalhar nos piaçabais (REZENDE, 2011). Nesse contexto de redefinição social, cultural e econômica da Amazônia os salesianos se instalam na região e durante quase um século as missões do Alto Rio Negro levaram evangelização, educação e saúde às/aos povos indígenas. A chegada da "civilização", contudo, tinha um preço.

Olhar, ouvir e escrever: desafios na compreensão da Educação Salesiana na Região do Alto Rio Negro

Retomamos a relevância do uso da etnografia e da observação como instrumentos de auxílio para a compreensão e documentação desse universo. Roberto Cardoso de Oliveira em "O trabalho do antropólogo: olhar, ouvir, escrever" enfatiza a relevância das três ações no trabalho de campo a fim de que informações coletadas/produzidas pelo pesquisador possam trazer uma maior compressão para a realidade estudada (OLIVEIRA, 2000). 
[...]O olhar: Talvez a primeira experiência do pesquisador de campo - ou no campo - esteja na domesticação teórica de seu olhar. Isso porque, a partir do momento em que nos sentimos preparados para a investigação empírica, o objeto, sobre o qual dirigimos o nosso olhar, já foi previamente alterado pelo próprio modo de visualizalo.[...]O ouvir: Se, aparentemente, a entrevista tende a ser encarada como algo sem maiores dificuldades, salvo, naturalmente, a limitação linguística - isto e, o fraco domínio do idioma nativo pelo etnólogo -, ela torna-se muito mais complexa quando consideramos que a maior dificuldade está na diferença entre "idiomas culturais", a saber, entre o mundo do pesquisador e o do nativo, esse mundo

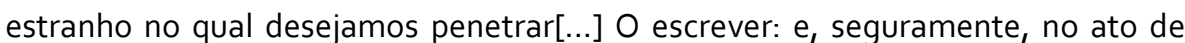
escrever, portanto na configuração final do produto desse trabalho, que a questão do conhecimento torna-se tanto ou mais crítica [...] (OLIVEIRA, 2000, p. 19-24).

Neste sentido, no final do ano de 2012 e graças à divulgação do Projeto de Plantas Medicinais, a equipe do NUGLAN (Núcleo Gestor de Estudos Linguísticos e Antropológicos do IFAM/CSGC) fez uma visita de campo à Região do Waupés para apresentar o projeto às comunidades reunidas em Assembleia, na comunidade Loiro, próximo a lauaretê. Na ocasião foi possível colher diversos relatos a respeito de como se deu a implantação das missões salesianas na região em questão.

No trajeto, passamos por diversos sítios arqueológicos e foi possível acompanhar a evolução da viagem da Cobra-canoa (mito criacional dos povos tukano) até a chegada no Alto Waupés. Serra da panela é um dos lugares míticos onde os deuses Tukano travaram lutas históricas contra seres encantados que pretendiam exterminar a humanidade, e foi visitado no caminho pelo rio Waupés até Loiro. Vale aqui relembrar rapidamente o mito de criação dos povos Tukano para que fique clara a relevância do mesmo na cultura local.

Os membros da família linguística Tukano oriental afirmam ter um passado em comum. Sua origem mítica está ligada ao Mito da Cobra-Canoa ou Canoa da Transformação. Segundo essas etnias, seus avós míticos foram trazidos do mundo espiritual para esse mundo que hoje habitamos no ventre de uma grande cobra que começou sua jornada no Lago do Leite (onde hoje está localizada a Baía da Guanabara, na região Sudeste) e foi subindo pelo litoral. Toda vez que ela saía do rio subterrâneo, por onde estava transitando, para respirar, deixava um pedaço da humanidade. Assim foi até a sua chegada à região do Waupés, na Cachoeira de Ipanoré, onde o restante da humanidade "desembarcou", dando origem aos povos que lá vivem. A hierarquia e a aplicação de critérios de aliança e arranjos sociais originaram-se da relação que essas etnias desenvolveram em virtude de sua origem mitológica. 
De certa forma a Cobra-Canoa que as "gestou" foi responsável pela configuração das relações étnicas da região. As demais famílias linguísticas e as respectivas etnias que compõem o sistema interétnico embora tenham também uma origem míticanão são considerados "parentes" pelos povos Tukano por não terem sido abrigadas pela Cobra. De forma extremamente resumida esse é o mito de criação desta etnia. Quando as estruturas étnicas talhadas no decorrer de várias gerações são colocadas à prova pela presença salesiana, nós vemos a mudança, sob diversas formas, das relações que antes eram regidas por regras deixadas pelos "legisladores", pelos avós da humanidade, como as regras de casamento interétnico e a reverência aos valores ancestrais. A herança da Cobra-Canoa vai sendo, pouco a pouco, deixada de lado.

Retomemos o relato etnográfico sobre a visita à Região do Rio Waupés por volta das 6 da tarde do primeiro dia, quando a luz natural já começava a ficar esmaecidas e percebemos uma claridade, ao longe. "Não há cidades nessa região. Que claridade é essa?". Depois de uma curva no rio se delineou, do meu lado esquerdo, o que parecia ser uma pequena cidade.

Taracuá foi a primeira missão salesiana instalada no rio Waupés. Com uma grande igreja do mesmo porte que a da Matriz em São Gabriel da Cachoeira, um hospital e uma escola, grandes construções erguidas no meio da floresta Amazônica que nos impressionaram e intrigaram "Como trouxeram os tijolos pra cá? Quem levantou essas construções tão grandiosas? Havia a necessidade de trazer muitos trabalhadores para construir essas estruturas".

Passada a surpresa inicial nos instalamos no centro comunitário e fomos para o rio tomar um banho, para depois comermos. Era uma noite de lua e certamente não havia a necessidade das luzes artificiais. Já no alojamento com companheiros da região conversamos longamente a respeito de como foram construídas aquelas estruturas. O que contaram foi que quando os padres chegaram a primeira coisa que fizeram foi convencer as famílias da necessidade de dar educação de branco para seus filhos.

Os meninos entre 5 e 14 anos ficariam em sistema de internato. A Pedagogia Preventiva calcada no tripé Razão, Religião e Amabilidade vem/é considerada como fator de formação desses jovens e de transformação da sociedade. Para construir aquelas estruturas os padres deram treinamento a um grupo de trabalhadores, entretanto, a obra não teria sido 
possível sem a igual colaboração dos alunos da missão que também trabalharam em sua construção.

Os relatos contam que nem sempre os pais e as crianças saíam voluntariamente de perto de suas famílias, sendo, nos casos de resistência, levados, sob protestos, para a missão. Dentro da missão os evangelizadores cuidavam para que os jovens aprendessem Português, Matemática, uma profissão e se tornassem bons cristãos e bons cidadãos, para o que era necessário um corte abrupto com seu passado mítico. De agora em diante/Doravante era proibido falar na língua materna, estando/ficando o transgressor sujeito às punições mais diversas, chegando até ser usado o castigo físico. Na década de 1970, contam os relatos, além do português era permitido falar tukano na missão de Pari-Cachoeira.

Saímos no dia seguinte às 6 da manhã em direção a Ipanoré, onde deveríamos descer da voadeira e fazer uma parte do trajeto de caminhão, em virtude da grande cachoeira localizada no lugar. Segundo o mito da Cobra-canoa foi em Ipanoré que ela saiu do rio subterrâneo, emergiu e deu origem à humanidade, no Waupés. No período de seca é possível, inclusive, vermos o buraco de onde ela saiu: uma cratera muito profunda e muito larga na pedra. Enquanto esperávamos nossa carona de caminhão, continuamos nossa conversa. Existiu ali onde estávamos uma grande Casa do Conhecimento. Era uma das maiores da região e abrigava muitas pessoas em dias de festa, servindo para vários rituais. Em um dia desses chegaram os missionários salesianos. Ao descerem da canoa os evangelizadores deram ordem para que queimassem a grande casa que, na visão cristã, abrigava práticas pagãs e profanas. A reação das pessoas foi de espanto e desolação com a destruição da Casa onde eram guardadas as memórias de seus ancestrais. Os coxos usados para fabricação do caxiri foram jogados no rio e, de forma melancólica, os povos da região viram arder a última grande Casa do Conhecimento.

Chegamos a Loiro por volta das 16 horas do segundo dia. Alguns de nós resolvemos descansar enquanto outros foram visitar lauaretê, sede do distrito que fica a cerca de 30 minutos de voadeira da comunidade de Loiro. Com uma estrutura que rivaliza facilmente com a sede do município, lauaretê possui comércio e um Pelotão Especial de Fronteira do Exército Brasileiro (PEF). Ao longe vemos a grande igreja erguendo-se na parte mais alta do lugar e, ao seu lado, o majestoso Colégio São Miguel. Absolutamente fantástico, construído no meio da floresta amazônica com os mesmos recursos que as construções de Taracuá, mão-de-obra treinada pelos padres e presença de alunos internos. Na capela, que fica ao lado 
da escola, encontra-se uma cruz que os indígenas entregaram aos salesianos quando esses lá chegaram; provavelmente, ela pertencia à Ordem dos Jesuítas que marcou sua presença no outro lado da fronteira. Bem próximo ao Colégio temos o rio Papuri, que faz fronteira natural com a Colômbia. Dali dá para ver a famosa Cachoeira da Onça. Descendo próximo ao porto, encontramos formações rochosas de diversos tamanhos, todas com marcações e desenhos muito antigos. Foi ali que o primeiro "cunhado" Tariano apareceu pedindo socorro, pois estava flechado e foi levado ao outro lado do rio pelo cacique Tukano, que o acolheu e, mais tarde, o recebeu por genro. Com o tempo esse agora "parente" trouxe a família para ali morar e é por isso que os Tariano, apesar de falantes do Aruwak, falam Tukano também.

Durante nossa visita conversamos com alguns membros da etnia Arapaçu, que nos relataram não falar a sua língua materna há muito tempo. De acordo com o relato, houve uma grande guerra -- muito antes da chegada dos brancos, num tempo que eles não conseguem precisar -- envolvendo essa etnia, guerra que causou muitas mortes e cujas crianças sobreviventes foram adotadas nas comunidades Tukano, na condição de "irmãosmenores".

Em conversa com os comunitários foi possível levantar dados importantes a respeito da vida na região e das necessidades básicas. A área em questão possui 04 etnias falantes de Tukano: Tukano, Tariano, Waik'hana (Pira-tapuia) e Arapaço. As comunidades, em sua maioria, não possuem energia elétrica e quando a tem é por meio de um pequeno gerador. Não há fossas sépticas nem água encanada, poucas possuem AIS (Agente Indígena de Saúde) e nenhuma recebe com regularidade a visita de dentista, bem como médicos especialistas. Entretanto, quando perguntados sobre suas prioridades mais urgentes a grande maioria demonstrou preocupação com a educação.

Poucos recursos, poucas salas, quase nenhum apoio, ausência de um PPP (Projeto Político Pedagógico) dificultam as atividades dos docentes que não podem oferecer um trabalho mais eficiente em virtude dessa carência São Gabriel da Cachoeira faz parte do Território Etnoeducacional do Rio Negro e vem procurando melhorar a educação escolar indígena na região, que, contudo, se defronta com obstáculos os mais diversos. A valorização e revitalização de conhecimentos tradicionais se tornam difíceis tendo em vista o desconhecimento e despreparo das novas gerações para lidar com os mesmos, pois a marca da educação salesiana ainda está presente nas escolas da região, seja em sua estrutura administrativa, seja em sua filosofia educacional. 
No âmbito educacional, as escolas da região ainda seguem os padrões estabelecidos pelos salesianos, formando "bons cidadãos". Por longo tempo a formação recebida não dava condições de o indivíduo questionar ou opinar, contudo, quando a igreja faz a opção pelos pobres, na década de 1960, há uma reformulação na catequese e a geração que irá lutar pelos direitos indígenas -- terra, saúde e demarcação -- é formada nesse contexto.

\title{
A Presença Evangélica: O Efeito Sophie Müller
}

\begin{abstract}
A ação do SPI, aqui, assim como em muitas áreas isoladas, torna-se quase ilusória, devido de um lado à falta de fundos e, por outro, à falta de pessoal sensível. [...] Quando muito, o delegado, monopolizando a exploração dos índios, pelo menos evita que sejam explorados por todos. Com esses escândalos e dilemas absurdos, o SPI é obrigado a contar com ... a falta de recursos e pessoal competente. (Nimuendaju, 1950, p. 127 apud WRIGHT, 2005).
\end{abstract}

O fenômeno evangélico entre os indígenas da Região do Alto Rio Negro deve ser visto como algo resultante de um contexto de exploração, cujo dominador branco impõe sua presença, obrigando os nativos a trabalhar de forma compulsória em suas grandes extensões de terra, além da exploração promovida pelo endividamento das comunidades junto aos comerciantes. A forma como o evangelho surge na vida dessas populações se contrapõe ao que até então vinha sendo feito pela Igreja Católica e pelo Estado Brasileiro.

Para entendermos os fatos é necessário relembrarmos o passado histórico da região, nos deteremos na Região do Rio Içana, onde teve início esse movimento que, rapidamente, se espalhou pelo rio Xié. A exploração da borracha e da balata, realizada de forma brutal por comerciantes colombianos e venezuelanos levou à morte e fuga de inúmeros indígenas do Içana, nas primeiras décadas do século XX. O panorama no Waupés era um pouco diferente, conforme podemos observar das palavras de WRIGHT (2005).

\footnotetext{
Das duas organizações missionárias presentes na região nessa época - os monfortianos no alto Papuri, desde 1915, e os salesianos no Uaupés (Jauareté e Taraqua) desde 1914 - a primeira parece ter tido efeito pouco duradouro em controlar o tráfico de trabalhadores, educar ou converter os índios, e foi até acusada por um agente do SPI como "simplesmente comerciantes da borracha (WRIGHT, 2005, p. 215)
}

Por outro lado, os Salesianos eram considerados, pelos agentes no Waupés, como o modelo de assistência que a população indígena precisava. De acordo com um agente que escreveu em 1932, "todos estariam perdidos se não fossem os salesianos que continuam seu 
trabalho maravilhoso" (Ofícios Recebidos dos Postos Indígenas do Alto Rio Negro, 1932), acrescentando que a solução para os problemas da área permanecia na proteção do incontrolável tráfico de trabalhadores através das escolas, desenvolvimento agrícola, artes e estabelecimentos educacionais (ibid.) que os Salesianos ofereciam (para uma visão comparativa e mais crítica, ver Nimuendaju, 1950)". Para os indígenas do Içana, entretanto, a configuração era outra: a presença salesiana e do Serviço de Proteção ao índio até a década de 1940 na região era praticamente nenhuma o que favoreceu a exploração brutal destes povos por parte dos produtores de borracha colombianos.

\footnotetext{
Nimuendaju e o Marechal Boanerges Lopes de Sousa (que pesquisou a região um ano depois de Nimuendaju) mencionam dois: Natividade Rivas, que freqüentemente levava Baniwa para trabalharem balata no Rio Papunaua, na Colômbia, e era conhecido por sua exploração na venda de mercadorias; e Antônio Maia, instalado em Yutica, no alto Uaupés, conhecido por seu mau trato dos índios e que foi morto, pelos próprios índios, em 1927. Valentim Garrido assumiu o papel auto-nomeado de seu pai como "Delegado dos índios do Içana", designando chefes locais para organizarem o trabalho, até a chegada do SPI no final da década de 40. (WRIGHT, 2005, p. 210).
}

Sarampo e doenças de pele que eram inexistentes entre os Baniwa antes de sua inserção compulsória na extração de borracha, tornam-se lugar comum entre os indígenas. O resultado efetivo do extrativismo sobre os Baniwa durante as três primeiras décadas do século XX resultou na fuga de comunidades inteiras para longe do raio de ação desses extratores de borracha. O declínio da produção da borracha na região resultou em mais mortes e desespero. Populações inteiras foram dizimadas do lado venezuelano, enquanto no lado brasileiro o controle era exercido com mão de ferro pelo comerciante Garrido até a sua morte em 1921 (WRIGHT, 2005).

O regime de extração da balata era fundamentado na violência e agressão mútua. Atrocidades cometidas contra os indígenas eram vingadas com o assassinato de comerciantes. As famílias -- os Garrido e os Manduca -- que dominavam o comércio batiamse pelo domínio da região (WRIGHT, 2005). Sem dúvida, a presença do elemento branco, tanto comerciantes quanto representantes do Estado brasileiro ou da Igreja, foi nesse momento extremamente destrutiva em virtude da forma como foram conduzidas essas relações.

A Segunda Guerra Mundial traz de volta o interesse do mundo pela borracha amazônica e, novamente, parte da população local é levada a trabalhar para eles. Mais uma 
vez há um tráfico intenso e ilegal dos Baniwa para território colombiano, endossada pelo SPI. O êxodo da população local por força da crueldade das famílias Garrido e Manduca, que exploravam a balata e a borracha, ainda hoje é lembrado pelos mais velhos. Os agentes do Estado brasileiro servem, nesse momento, de agenciadores da mão de obra para os que ficaram na região, e a ausência da Igreja Católica no Içana, até aquele momento, colabora para tal fato.

Nesse contexto surge Sophie Muller, missionária americana de tendência claramente messiânica que percorreu a Região do Içana a partir da Colômbia. Foi uma das responsáveis por traduzir o Evangelho para a língua baniwa. A mensagem pregada por ela seria um contraponto à situação dos indígenas da região. Seus discípulos, cada vez mais numerosos, transmitiram sua doutrina pela região, o que chamou a atenção das autoridades de São Gabriel. Os salesianos assim descrevem essa invasão protestante:

Empenhados com a nova missão salesiana de (S. Isabel) iniciada em 1942 para neutralizar a propaganda dos Batistas do Colégio de Jucaby, perto de Uaupés [São Gabriel], os Salesianos conseguiram, com a graça de Deus e com o visível auxílio da Mãe Celeste, quase plena vitória. Neste Interim de mais de 6 anos, os protestantes trabalhavam clandestinamente, penetrando pelas fronteiras de Colombia e Venezuela ao Brazil, minando todo o território do rio Içana e seus afluentes com o veneno da heresia... (Crónica da Nova Missão Salesiana, de Assunção, Rio Içana, Fundada aos 8 de Fevereiro de 1951. Arquivos Salesianos, Missão Assunção, Rio Içana, Prelazia do Rio Negro; doravante, Diários Salesianos)" (WRIGHT, 2005, p.223).

Os salesianos encontravam-se empenhados em estabelecer a missão de Santa Isabel do Rio Negro no período em que ocorreram esses fatos o que, em parte, explica sua ausência na região. Após o sucesso de Sophie Muller é que finalmente a Igreja Católica se instala no Içana, em 1951.

A presença da New Tribes Mission representava para o Estado brasileiro uma grande ameaça, pois comprometia a segurança de nossa fronteira. O delegado do S.P.I no Içana, Ataíde Cardoso, registrou várias queixas formais sobre a forma de evangelização da missionária. Uma delas é que a mesma gerava conflitos dentro das comunidades quando parentes se recusavam a aceitar a fé protestante. A segunda queixa, tida como a mais grave pelo órgão, é o não reconhecimento da autoridade do Estado brasileiro na região. A luta travada pelas almas dos índios Baniwa no rio Içana, iniciada nos anos 1950, tem grande repercussão no meio militar, pois os protestantes eram acusados de insurgência e desobediência. No ano de 1961 os militares de Cucuy expulsam Henry Loewem, um dos 
pastores responsáveis pela guerra de propaganda contra a Igreja Católica e o Estado brasileiro (WRIGHT, 2005). A presença de Sophie e seus seguidores no Içana traz instabilidade à região. O status quo foi abalado pelas ideias libertárias e insurgentes pregadas pela missionária, e pelos adeptos do protestantismo que por lá se instalaram.

As concepções educacionais adotadas até então estavam diretamente ligados à educação salesiana ou de influência pentecostal, no último caso proporcionada pelas igrejas protestantes que se instalaram no município. Subitamente, os antepassados tornam-se sombras cada vez mais distantes das lembranças do povo e seus ensinamentos vão se esmaecendo dia-a-dia. Ocorre a demonização dos costumes tradicionais e seu consequente abandono por parte das comunidades que abraçaram a nova fé.

Entre os povos Nadahup (Maku), a fé protestante também foi profícua. As etnias pertencentes ao tronco Nadahup são däw, nadöb, hupda, yuhupdé, todas oriundas, igualmente, da cobra-canoa (mito criacional dos povos Tukano). Nos deteremos, aqui, no povo däw, o qual tivemos oportunidade de visitar para apresentar o projeto de plantas medicinais. As etnias do tronco Maku são profundamente estigmatizadas. Dentro da sociedade gabrielense são nomeados, pejorativamente, de kamã, lapiri e [onde] o próprio termo Maku é visto/usado como xingamento. São populações espalhadas pela região do Waupés, onde convivem com as etnias Tukano, mitologicamente, tendo participado da jornada da Cobra-canoa com eles. Porém pesa sobre eles o estigma de bêbados e desleixados.

Os däw, em determinado período, foram impelidos a ir para a região de Santa Isabel do Rio Negro, para trabalhar na extração de piaçaba, entretanto, acabam se tornando dependentes de álcool e extremamente endividados junto aos regatões. Nos idos dos anos 1990 missionários evangélicos canadenses compram uma área em frente a São Gabriel da Cachoeira e oferecem a mesma aos däw, que se convertem ao pentecostalismo e abandonam as tradições.

Em nossa visita foi possível observar a dinâmica da comunidade e fazermos apontamentos. A comunidade possui uma escola municipal que está em péssimo estado de conservação. As casas são, em sua maioria, feitas de madeira e sem banheiro, a única exceção sendo a casa dos missionários que, esporadicamente, visitam a localidade. A mesma é ampla, de alvenaria, e com banheiro, como já mencionado. Ali havia uma bomba d'água que estava 
inoperante por falta de um fusível que a fizesse funcionar. Outra estrutura bem construída era a igreja, com meia parede de alvenaria e telhado firme.

Ao explicarmos o projeto aos professores da aldeia, colocamos a necessidade de documentar os conhecimentos tradicionais dos antigos pajés. Um dos professores fez a seguinte declaração: "Professora, a gente aqui não precisa mais dessa história de pajé não, nós agora temos Jesus e temos remédios". Embora nem todos os membros compartilhem dessa visão, já é nítido que a juventude que cresceu longe dos conceitos tradicionais os rejeitam de forma veemente. Em nenhuma das comunidades visitadas a presença da igreja (seja qual for a denominação) garantiu a construção de fossas sépticas ou de escolas adequadas, na verdade, as igrejas mantêm suas estruturas ao lado da pobreza e abandono das comunidades. É sabido que essa responsabilidade pertence ao poder público, porém, é gritante ver uma escola caindo aos pedaços e, ao lado, a casa dos missionários construída em alvenaria.

O processo de contato com a sociedade regional iniciado bem antes da chegada dos missionários salesianos e dos evangélicos está em andamento e não há como saber seu desfecho. O fato é que os povos indígenas da região foram atingidos em seu âmago e suas estruturas sociais, culturais, políticas e econômicas reconfiguradas devido também à presença desses religiosos. Apesar das pressões da sociedade envolvente, que insiste em fazê-los/torná-los "civilizados", esses povos seguem resistindo corajosamente, e lutam, através de suas representações junto ao Movimento Indígena, pela manutenção de suas terras, sua língua e suas conhecimentos tradicionais

\section{Considerações Finais}

As reflexões deste estudo realizadas através da observação etnográfica de atividades de pesquisa realizadas pelo Núcleo Gestor de Estudos Linguísticos e Antropológicos, NUGLAN, do Instituto Federal de Educação, Ciências e Tecnologia do Amazonas - Campus São Gabriel da Cachoeira, IFAM CGSC, tiveram como escopo principal a compreensão da concepção de educação oferecida pelos padres Salesianos na Região do Alto Rio Negro. Nesse contexto de redefinição social, cultural e econômica da Amazônia os salesianos se instalam na referida região e durante quase um século as missões levaram evangelização, educação e saúde aos povos indígenas. Contudo, a chegada da "civilização" teve um preço. 
A vida das etnias indígenas no Alto Rio Negro organizadas socialmente desde o início dos tempos pelos conhecimentos tradicionais, os quais eram estabelecidos através da mitologia que os ensinou a organizar seu cotidiano, a aproveitar os elementos da natureza e a explorar, de forma respeitosa, os recursos por ela oferecidos. Esses ensinamentos, passados de geração para geração, foram reconfigurados através da necessidade de "integração nacional" apregoada pela nascente República no final do século XIX e ganhando força no governo Vargas, na década de 1930, como já explicitado anteriormente.

Devido a tais impactos, o conhecimento mitológico presente ainda hoje entre os povos indígenas do Alto Rio Negro pouco a pouco foi perdendo força em virtude da pressão sofrida para sua integração à sociedade nacional. Mais especificamente ela é reflexo da educação oferecida pelos padres Salesianos às inúmeras etnias da região. Uma concepção de construção de conhecimento que fez com que as tradições ancestrais de povos milenares fossem colocadas em xeque.

Consideramos relevante afirmar que as concepções educacionais adotadas contemporaneamente sofrem a influência da educação salesiana ou pentecostal, nesse último caso proporcionada pelas igrejas protestantes que se instalaram no município. E como os antepassados se tornassem sombras cada vez mais distantes nas lembranças dos povos e seus ensinamentos se desvanecessem dia-a-dia. Nesse contexto acontece a demonização dos costumes tradicionais e seu consequente abandono por parte das comunidades que abraçaram a nova fé.

Assim, a necessidade de manter-se conectado à sua herança ancestral fará com que as crianças e jovens indígenas reconheçam a relevância das tradições, valorizem a mitologia criacional apesar das influências externas procurarem debelar os esforços da resistência cultural. A luta pela terra e por saúde foram as bandeiras iniciais do movimento indígenas, hoje, além delas, a educação é ponto focal das reinvindicações do movimento. Uma educação que seja humanística, entretanto mantenha o valor dos conhecimentos tradicionais, é o desafio para as próximas gerações de líderes.

Esforços vêm sendo empreendidos pelo movimento indígena a fim recuperar suas heranças culturais e manter a identidade étnica dos grupos. Ações junto ao poder público e a cobrança de políticas que atendam aos povos bem como o fortalecimento de associações representativas que buscam soluções na área da saúde, educação e demarcação das terras. Esse grande desafio de lutar por seus direitos, sua língua e suas heranças permanece como 
foco central das vidas desses povos. No rastro da Cobra-canoa os indígenas do alto Rio Negro seguem firmes em buscam de soluções para os desafios de ser índio na vida moderna na sociedade brasileira.

\section{Referências}

ALBUQUERQUE, Judite. Captura e resistência: Efeitos do sistema Preventivo de educação Salesiana entre índios do Rio Negro/AM. In: SEMINÁRIO DE ESTUDOS EM ANÁLISE DO DISCURSO. 2., 2005, Porto Alegre. Anais eletrônicos.... Porto Alegre, 2005. Disponível em: < http://anaisdosead.com.br/2SEAD/SIMPOSIOS/JuditeGoncalvesDeAlbuquerque.pdf $>$. Acesso em: 22 mai. 2016

BAGNO, Marcos. Preconceito Linguístico: O que é? Como se faz. Disponível em $<$ https://escrevivencia.files.wordpress.com/2014/03/marcos-bagno-preconceitolingczbcc3adstico.pdf >.Acesso em: 24/04/2016

BOMBARDI, Fernanda Aires. Políticas Indígenas e indigenistas: descimentos particulares de índios na Amazônia colonial (1680 - 1747). In: SIMPÓSIO NACIONAL DE HISTÓRIA - ANPUH 2011, São Paulo. Anais eletrônicos.... São Paulo, 2011.

CAMARGO, Dulce Maria Pompeo; ALBUQUERQUE, Judite Gonçalves de. O Eu e o outro no Ensino Médio Indígena: Alto Rio Negro (AM). 2002. Disponível em: <http://www.scielo.br/pdf/es/v27ng5/a07v2795.pdf $>$. Acesso em: 24/04/2016

CAMPBELL, Joseph. As Transformações do Mito. São Paulo: Cultrix. 2015 Mito e Transformação. São Paulo: Ed. Ágora. 2008.

CARDOSO, Fernando Henrique. Pensadores que inventaram o Brasil. São Paulo: Companhia das Letras. 2013

COSTA, Renilda Aparecida. Dissertação de Mestrado - UNIPLAC - 2011. Identidade Nacional Brasileira e a Educação: Homogeneidade X Pluralidade Cultural.

FREIRE, Paulo. Pedagogia da Autonomia: Saberes necessários à prática educativa. São Paulo: EGA. 1996.

JÚNIOR \& WEISSEBÖCK, Celso Herold e Manuela. Etnia e educação: a escola "alemã" do Brasil e estudos congêneres. Florianópolis/Tubarão-SC: Editora da UFSC / Editora da UNISUL, 2003. 258 p. Revista eletrônica HISTEDBR. Disponível em:

$<$ http://www.histedbr.fe.unicamp.br/revista/edicoes/33/res02_33.pdf >. Acesso em: 24/04/2016. Resenha Neide Almeida Fiori.

MAIA, Marcus. Manual de Linguística: subsídios para a formação de professores Indígenas na área de linguagem. MEC - 2006. Série Via dos Saberes.

Mapa-livro FOIRN - 1998

REZENDE, Justino Firmino. A presença salesiana no Alto Rio Negro: Tópicos de contextos históricos - ENCONTRO DAS SALESIANAS - JUNIORISTAS. Santa Isabel do Rio Negro, set., 2011. Disponível em: 
$<$ http://www.adital.com.br/arquivos/2011/og/pt\%20justino\%2opresen\%C3\%A7a\%2osalesiana\%2on 0\%2orio\%2onegro.pdf>. Acesso em: 24 abr. 2016

RIBEIRO, Darcy. O Povo Brasileiro: A formação e o sentido do Brasil. São Paulo: Companhia das Letras, 1995

SEYFERTH, Giralda. A conflituosa história da formação da etnicidade teuto-brasileira. Etnia e educação: a escola "alemã" do Brasil e estudos congêneres. Revista eletrônica HISTEDBR. Florianópolis: Editora da UFSC; Tubarão-SC: Editora da UNISUL, 258 p., 2003.

SMILJANIC, Maria Inês. Os enviados de Dom Bosco entre os Masiripuwëteri: O impacto missionário sobre o sistema social e cultural dos Yanomami Ocidentais (Amazonas, Brasil). Journal de la société dês américanistes. p. 88, 2002. Disponível em: $\langle$ https://jsa.revues.org/2763 $\rangle$. Acesso em $24 \mathrm{abr}$. 2016.

TOLEDO, GIATTI \& PELICIONI. Urbanidade rural, território e sustentabilidade: relações decontato em uma comunidade indígena no noroeste amazônico. 2008. Disponível em: $<$ http://arca.icict.fiocruz.br/handle/icict/1910 . Acesso em: 23/06/2016

WRIGHT, Robin. História indígena e do indigenismo no Alto Rio Negro. Campinas, SP: Mercado das Letras; SP. ISA .2005.

\begin{abstract}
The present reflections are the result of the observation and executin of activities at Manager Center for Language and Anthropological Studies, NUGLAN, from Federal Institute of Education, Science and Technology of Amazonas - Campus São Gabriel da Cachoeira, IFAM CGSC, and of teaching activities carried out between The years 2011 and 2013 . We sought to understand the model of education offered by the Salesian Fathers in the Upper Rio Negro for the many ethnic groups in the region and to point out the impact they had on the arrival of evangelical missionaries in society. The construction of churches, schools, hospitals brought changes in the way of life and the adoption of a new language. There are reports of a ban on the use of the mother tongue and the use of punishment for those who transgress the norms, but what has resulted from this relationship that goes beyond physical punishment. The arrival of the Pentecostal church has an impact on the life of the communities that have assumed the evangelical position, leading to the demonization of their traditions. We need to understand the implications of the education offered by priests and the effect of the evangelical presence on indigenous communities.
\end{abstract}

Key words: Religion, Culture and Educacion in Upper Rio Negro. 